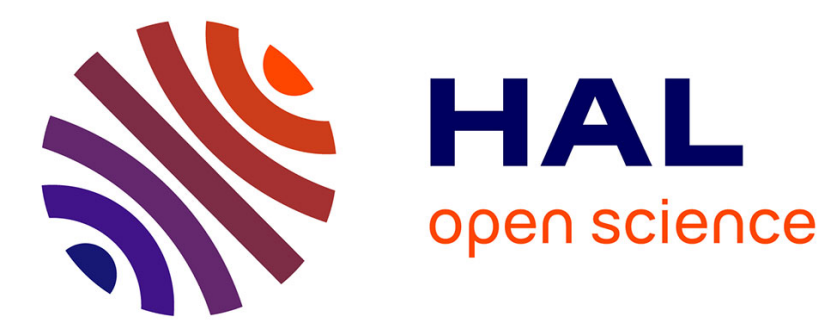

\title{
Reliability analysis of tube hydroforming process
}

Bouchaib Radi, Abel Cherouat, Abdelkhalak El Hami

\section{To cite this version:}

Bouchaib Radi, Abel Cherouat, Abdelkhalak El Hami. Reliability analysis of tube hydroforming process. QUALITA2013, Mar 2013, Compiègne, France. hal-00823167

\section{HAL Id: hal-00823167 \\ https://hal.science/hal-00823167}

Submitted on 16 May 2013

HAL is a multi-disciplinary open access archive for the deposit and dissemination of scientific research documents, whether they are published or not. The documents may come from teaching and research institutions in France or abroad, or from public or private research centers.
L'archive ouverte pluridisciplinaire HAL, est destinée au dépôt et à la diffusion de documents scientifiques de niveau recherche, publiés ou non, émanant des établissements d'enseignement et de recherche français ou étrangers, des laboratoires publics ou privés. 


\title{
Reliability Analysis of Tube Hydroforming Process
}

\author{
Bouchaib Radi \\ Dept. Technics \\ FST Settat \\ BP : 577, Route de Casablanca, Settat, Morocco \\ Bouchaib.radi@yahoo.fr
}

\author{
Abel Cherouat \\ Gamma3 \\ University of Technology Troyes \\ 12 rue Marie-Curie, BP 2060, 10010 Troyes, France \\ Abel.cherouat@utt.fr
}

\author{
Abdelkhalak El Hami \\ LMR \\ INSA Rouen \\ 76801 St Etienne du Rouvray, France \\ aelhami@insa-rouen.fr
}

\begin{abstract}
In this paper, we propose a reliability-mechanical study combination to treat the tube hydroforming process (THP). This process consists to apply an inner pressure combined to an axial displacement to manufacture the part. Our goal is the computation of the failure probability of the hydroforming process. Normally, this process is particularly complex and have to be solved numerically. There are several numerical techniques available to compute the solution. However, some design parameters are uncertain and the deterministic solutions could be unacceptable. Thus, a hydroforming process is an important subject for reliability analysis: the finite element method coupled with the first order reliability method (FORM). The definition of the limit state functions takes advantage from the forming limit curve (FLC) used as a failure criterion to detect the occurrence of wrinkling, severe thinning and necking. The THP is completely treated numerically to validate the proposed approach.
\end{abstract}

Key words-reliability, tube hydroforming process, forming limit curve, failure mode, first order reliability method (FORM).

\section{INTRODUCTION}

For the production of low-weight, high-energy absorbent, and cost-effective structural automotive components, hydroforming is now considered the only method in many cases. The principle of tube hydroforming process (THP) is shown in Fig. 1. The hydroforming operation is either a force controlled (the axial forces are varied with the internal pressure) or stroke-controlled (the strokes are varied with the internal pressure). Note that the axial force and the stroke are strongly interrelated (see Fig. 1). The hydroforming operation comprises two stages: free forming and calibration.

The main difficulty in many hydroforming processes is to find the convenient control of the evolution of the applied internal pressure and axial forces paths. This avoids the plastic flow localization which lead to the buckling or fracture of the tube during the process. In principle, all materials and alloys used for deep drawing or stamping can be used for hydroforming applications as well.

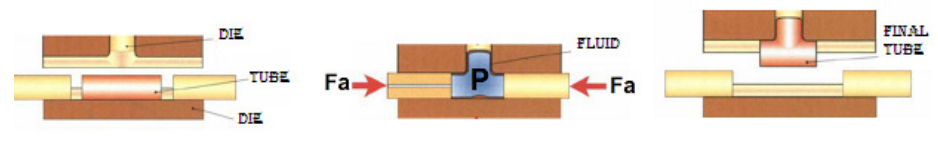

Fig. 1. Principle of Tube Hydroforming Process

In Ref. [1], it used a fully coupled constitutive equation accounting for the isotropic elastoplasticity, hardening and damage to improve hydroforming of thin tubes. The main objective is to avoid the ductile damage occurrence in order to obtain an acceptable final tube shape. The above mentioned THP studies are restricted on deterministic optimization, where it is assumed that all the design variables and parameters involved are certain. Practically, all real-life sheet metal forming are non deterministic, which involve some degree of uncertainties in the load path, lubricate situation, material properties, and geometries. These uncertainties can manifest during production and affect considerably the final quality of the part and their mechanical properties and can lead to the failure of the process. In this paper, we introduce the reliability analysis to identify the reliable path loading that allows obtaining a free part defects with considerations to the uncertainty included in the loading path, material properties, initial thickness of the tube and a new procedure is proposed to compute the probability of failure. This approach is based on the finite elements approximation and the first order reliability method (FORM) to compute the reliability index and the failure probability. 


\section{SOURCES OF UNCERTAINTIES IN THE METAL FORMING PROCESS}

In a sheet metal forming, several parameters have been set. Often, these parameters are tainted by uncertainty which may affect the stability of the process if they are not taken into account as early as the design phase. These fluctuations can come from materials parameters, geometrical parameters and the parameters related to the process such as loads, also contact problem. Other types of variability may also exist which are related to the environment such as temperature, humidity and also errors induced by the operator.

Many studies have highlighted the randomness of the sheet metal forming. These uncertainties may come from the variability associated with the material, the surface roughness and the initial thickness of the sheet. They may also come from tools that can undergo geometric changes because of wear and tear, changes of mechanical properties and temperature variation. All of these things can affect the final quality of the piece, without forgetting the variations that can affect shipments, as the force of the die or advance of the punch and the applied pressure. Lubrication also plays an important role in shaping of metals. This phenomenon is difficult to control, indeed, lubrication conditions can change in a global or local manner due to the roughness of the surface or the distribution of the temperature. For these reasons, their models and their idea is often approached in a comprehensive way across the structure. Other types of variability may exist as an incorrect machine or incorrect positioning of the piece or tools.

Some authors have real tests conducted to quantify the level change of certain parameters. In [2], they collect more than 45 samples of the same material and show that the variability in the level of strain-hardening coefficient reaches $14 \%$. This can affect significantly the rate of final thinning and also the final elastic return, after sheet metal forming. In [3], it shows that in this process, there are 12 parameters for which the method can have a high sensitivity. These settings include: coefficients of hardening, the flow constraint, anisotropy coefficients, the initial thickness of the die and coefficients of friction.

Taking into account random aspects or the spatial variability on the parameters allows us to better deal the probability of failure of the process and its stability. A probabilistic study of the process allows us to validate input parameters. In general, a metal forming process is regarded as stable when, even in the presence of the different fluctuations, the variance remains low at the level of the final characteristics of the piece, for example on the distribution of the final thickness, the rate of damage or the finale form of the metal piece. Some consider a metal forming process as stable when the rate of defective parts does not exceed $1 \%$.

\section{RELIABILITY ANALYSIS}

Structural reliability analysis [4,5] is an approach that assists the design engineer to take into account all possible uncertainties during the design and construction phases and the lifetime of a structure in order to estimate the probabilities of failure.
Let $X=\left(X_{1}, X_{2}, \ldots, X_{m}\right)^{T}$ be the random vector of the probabilistic analysis. To preserve the integrity of the structure, the failure mode must be defined and the corresponding limit state function $\mathrm{G}(\mathrm{X})$ established. In a unilateral contact problem with friction, the real contact surfaces and the contact reactions depend on the values of design parameters which are uncertain. Thus, excessive stresses or strains could appear in an element of the structure. The contact surfaces could not conform to a standard of a geometrical rule and lead to a structural failure. So, problems involving contact are an adequate domain for a reliability analysis. The structure is situated in its safe domain $D_{s}$ if $G(X)>0$ and it is situated in its failure domain $D_{f}$ if $G(X) \leq 0$. Then, the failure probability is:

$$
P_{f}=\operatorname{Pr}(G(X) \leq 0)
$$

Our purpose is the reliability analysis of the hydroforming process. In this situation, the analytical expressions of the limit state function $G$ and its derivatives are often not available in function of the physical random variables $X_{1}, X_{2}, \ldots, X_{m}$. Then, it is only possible to obtain the failure probability under an implicit numerical form. So, to solve our reliability hydroforming problem, a combination between the finite element method and the response surface method is proposed.

The response surface methods have been widely developed in nonlinear reliability analysis [6]. Several authors have proposed solutions to improve the accuracy of results, to decrease the number of necessary numerical calculations on FEM codes and to increase the robustness of the algorithms.

In our nonlinear study, we propose an adaptive surface method coupled with the first order reliability method (FORM). The sets of design points and the response surfaces are generated in the space of standard Gaussian variables.

\section{NUMERICAL RESULTS}

\section{A. Deterministic problem}

The geometry model as well as the dimensions of the tube is shown in Fig. 2. This model is composed of a matrix with the desired finale shape, a punch for the inputs to the expanded zone and tube of the original thickness of $1.5 \mathrm{~mm}$. The dimensions of the matrix and the tube are given in table 1.

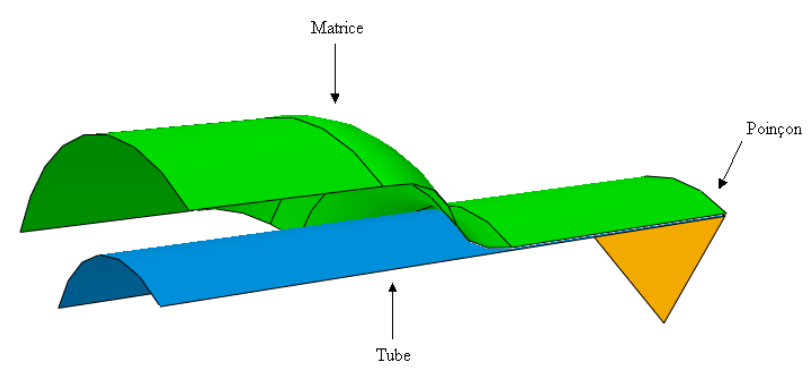




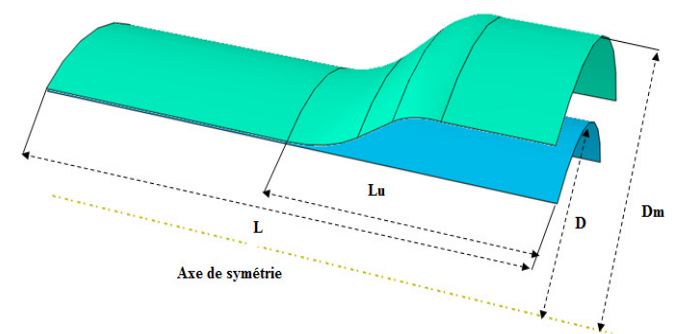

Fig. 2. Dimension of the tube and the die.

TABLE I. DIMENSIONS OF THE TUBE AND THE DIE

\begin{tabular}{|c|c|c|c|}
\hline $\mathrm{L}$ & $\mathrm{Lu}$ & $\mathrm{D}$ & $\mathrm{Dm}$ \\
\hline $80 \mathrm{~mm}$ & $35 \mathrm{~mm}$ & $20 \mathrm{~mm}$ & $33 \mathrm{~mm}$ \\
\hline
\end{tabular}

The other parameters of the DC04 steel materials are given in table 2. Young's modulus, Poisson's ratio and density are considered to be deterministic.

TABLE II. PARAMETERS FOR DC04 STEEL MATERIALS

\begin{tabular}{|c|c|c|c|}
\hline Material & $\mathrm{E}(\mathrm{MPa})$ & $\boldsymbol{\rho}$ & $\rho\left(\mathrm{kg} / \mathrm{m}^{3}\right)$ \\
\hline $\mathrm{DC} 4$ & 210000 & 0.3 & 7800 \\
\hline
\end{tabular}

The material is modeled by a Swift law, given by the following expression:

$$
\sigma=k \times\left(\varepsilon+\varepsilon_{0}\right)^{n}
$$

The road of load giving the axial displacement time is modeled by a linear line (see Fig. 3). Variation on displacement axial is taken into account through the amplitude. The route of load giving the internal pressure variation with time is modeled by 3 points $P_{1}, P_{2}$ and $P_{3}$ (see Fig. 4).

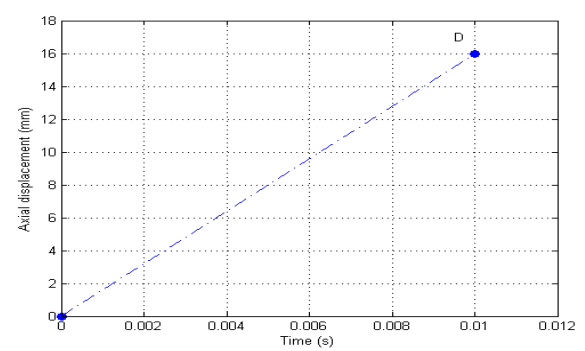

Fig. 3. Loading path: displacement (mm) - time (s).

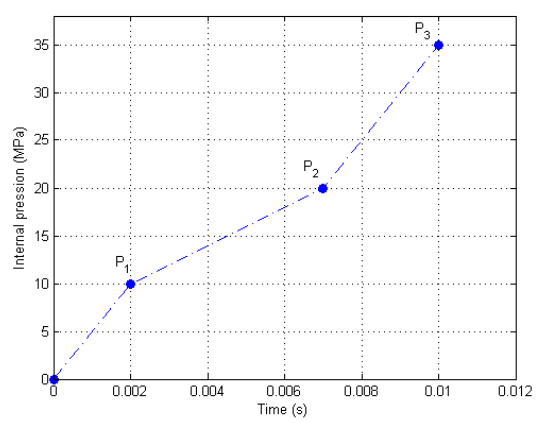

Fig. 4. Load path: pressure (MPa) - time (s).
Table 3 gives the values of different parameters used in the process:

TABLE III. RANDOM PARAMETERS

\begin{tabular}{|c|c|c|c|}
\hline$k(\mathrm{MPa})$ & $n$ & $P(\mathrm{MPa})$ & $D(\mathrm{~mm})$ \\
\hline 494 & 0.234 & 1 & 16 \\
\hline
\end{tabular}

\section{B. Finite element model}

The die and the punch are modeled by rigid bodies and are mesh with elements of type R3D4. The tube is modeled by a deformable body mesh with elements S4R shell with five points of integration in the thickness. Given the symmetry of the problem, it models a quarter of the model. The tube is mesh with 2480 elements. The finite elements code Abaqus/Explicit@ is used to all of numerical simulations of the THP.

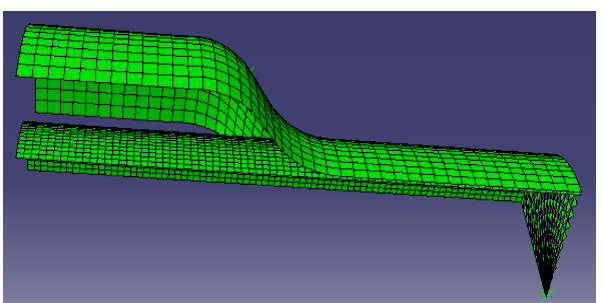

(a)Initial step

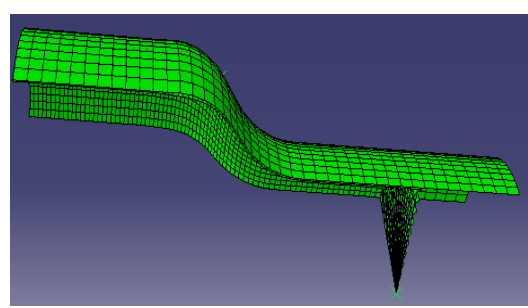

(b) Final step

Fig. 5. Finite element model.

\section{Choice of uncertain parameters}

Several parameters are being set in a formatting operation. Most of these settings are uncertain. In this work, we will be limited to the parameters on the properties of materials and the load. Hardening parameters $(k, n)$ and the load $\mathrm{P}$ are considered random. They are obtained from a free tire test. It is assumed that these parameters have a coefficient of variation of $10 \%$ and they follow normal laws. The probabilistic characteristics of these parameters are given in table 4.

TABLE IV. PROBABILISTIC CHARACTERISTICS of HARDENING

\begin{tabular}{|c|c|c|c|}
\hline $\begin{array}{c}\text { Random } \\
\text { variables }\end{array}$ & $\begin{array}{c}\text { Mean } \\
\text { value }\end{array}$ & $\begin{array}{c}\text { Variation } \\
\text { coeff. }(\%)\end{array}$ & Distribution \\
\hline$k(\mathrm{MPa})$ & 494 & 10 & Normal \\
\hline$n$ & 0,234 & 10 & Normal \\
\hline$P$ & 1 & 10 & Normal \\
\hline
\end{tabular}


THP generally involves two types of loads: internal pressure and axial displacement. Several studies have shown the sensitivity of the method with the parameters of loading. A variation of these parameters can affect the stability of the process and the emergence of some plastic instability. Taking account of these variability's allows us to better assess the reliability method.

\section{Failure criteria}

Two types of plastic instabilities are likely to appear in THP. In fact, excessive movement promotes tube folding while significant pressure can cause the collapse of tube. Obtaining a room without defects requires the control of these parameters. Assessment and control of these instabilities require the implementation of appropriate criteria for their predictions and their evaluations.

The forming limit curve (FLC) in the plane of principal strains is selected as the criterion of failure for the assessment of the likelihood of failure for both modes of failure. The choice of the FLC is also justified by its simplicity and its generalization regardless of the method and the type of solicitation from other criteria that requires additional development. Although open to criticism, its use is widespread in the industry and even also in research as a test for the control of operations in the form and in particular in THP. In reality, this curve despite the fact that it is often used for optimization and the development of some methods for formatting has mainly two major disadvantages: the first is its deformation path dependency. In fact, it is efficiency for proportional journeys, which is not the case in the development where several types of no-linearity's (nonmaterial and geometric linearity). The second disadvantage comes from the nature of the FLC, this curve is determined experimentally, hence its uncertain character. In our study, considering the variability that may make the FLC in admitting that it follows a law of probability. On the FLC, it defines two curves or functions to limit state: the first represents the limit of necking curve and the second the curve limited folding.

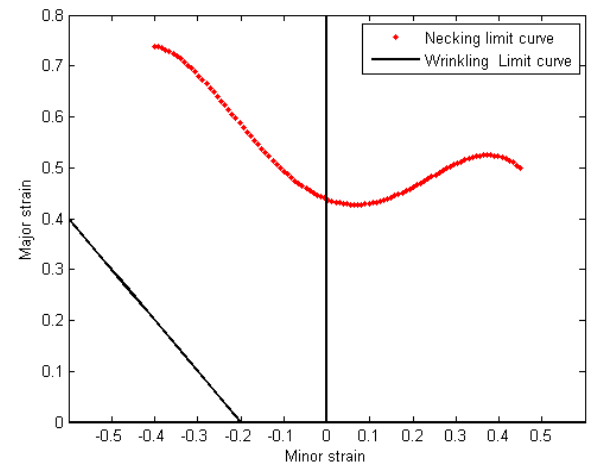

Fig. 6. Forming Limit Curve (FLC).

\section{E. Identification of the critical elements and critical areas}

The estimation of the probability of failure of the process requires in reality the estimation of the probability of failure for each element of the structure. For complex issues such as formatting this seems unworkable and requires huge computing resources. Level to this problem late, it proposes an approach which is based on the most critical of the structure element when all parameters are fixed to their nominal values. The identification of the critical element later allows us to define a critical zone around this element and which represents in fact an area location or the principal strains reach critical values. Later, this region presents a significant risk of failure which means that the probability of failure reached its maximum values in the area potential. This technique allows a drastic simplification of the problem in only interested critical area and at the same time has an idea on the spatial distribution of the probability of default.

Postponing the deformation state predicted in the end of the simulation on the forming limit curve, it identifies critical elements that are closest to these limits for each failure mode curves.

Fig. 7 shows the location these two elements on the structure. The folding is located at the level of the 696 element while the necking is located at the level of the element 2242. The critical area where the probability of failure is maximum is defined by all of the elements that surround the critical element for each failure mode. The extent of this area covers the 25 nearest items of the critical element. In reality this choice is up to the designer. Space determination of the probability of default critical element is a rational criterion for the assessment of the probability of default in formatting and allows you to get an idea on the level of reliability in a local way.

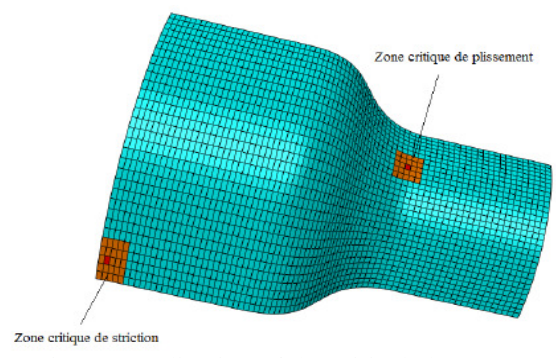

Fig. 7. Localization of the critical elements.

\section{F. Limit state functions}

In the proposed approach, based on a probabilistic characterization of major and minor strain reviews for the necking and folding so to access the likelihood of failure. These critical elements are characterized by their major deformations and their minor deformations noted by $\left(\varepsilon_{1}^{s}, \varepsilon_{2}^{s}\right)$ for the necking and $\left(\varepsilon_{1}^{w}, \varepsilon_{2}^{w}\right)$ for folding.

By superimposing minor and major of each element deformations on the forming limit curve, it was noted the deformations are of side left of the CFL. Thus, these two boundary curves will be modeled by linear equations of first order. The variables $P, k$ and $n$ are considered random. Analytically the limit state functions are expressed according to critical strain and are given by the following equations: 
$\left\{\begin{array}{c}G_{w}(P, k, n)=\varepsilon_{1}^{w}+\varepsilon_{2}^{w}-s \\ G_{s}(P, k, n)=\varepsilon_{1}^{s}+\alpha \varepsilon_{2}^{s}-\gamma\end{array}\right.$

where :

$\left(\varepsilon_{1}^{w}, \varepsilon_{2}^{w}\right)$ : the main major and minor wrinkling deformation respectively

$\left(\varepsilon_{1}^{s}, \varepsilon_{2}^{s}\right)$ : the main major and minor necking deformation respectively

$\gamma:$ the value of the FLC of necking

$\alpha$ : the director coefficient of the necking limit curve

$\mathrm{s}:$ the coefficient of security for the folding limit curve

\section{G. Reliability results}

In this hydroforming process, we want to show that the risk evaluation of failure occurring in the structure where some uncertainties exist and to use a reliability analysis to characterize the stress field in a THP. The proposed approach is based on the coupling between the FORM (Matlab code) and the numerical simulation based finite element method via ABAQUS/Explicit of the hydroforming process. To obtain information from the output file of the ABAQUS/Explicit, we use a developed Python code.

The obtained failure probability is of the order of $10^{-2}$ (see Table 5) and the design point components in the space of physical random variables relative to the wrinkling are given in Table 6.

TABLE V. FAILURE PROBABILITY AND RELIABILITY INDEX

\begin{tabular}{|c|c|c|}
\hline Iteration & $P_{f}$ & $\beta_{H L}$ \\
\hline 90 & 0.04638 & 2.1693 \\
\hline
\end{tabular}

TABLE IV. WRINKLING DESIGN POINTS

\begin{tabular}{|c|c|c|}
\hline$P^{*}(\mathrm{~Pa})$ & $k^{*}(\mathrm{~Pa})$ & $n^{*}$ \\
\hline 1156115.67 & 374196094.46 & 0.23177701 \\
\hline
\end{tabular}

TABLE VII. FAILURE PROBABILITY AND RELIABILITY INDEX (NECKING)

\begin{tabular}{|c|c|c|}
\hline Iteration & $P_{f}$ & $\beta_{H L}$ \\
\hline 100 & 0.0849 & 3.1388 \\
\hline
\end{tabular}

TABLE VIII. NECKING DESIGN POINTS

\begin{tabular}{|c|c|c|}
\hline$P^{*}(\mathrm{~Pa})$ & $k^{*}(\mathrm{~Pa})$ & $n^{*}$ \\
\hline 1222932.72 & 612938800.96 & 0.23483325 \\
\hline
\end{tabular}

A reliability analysis gives the importance of each random variable in the risk of failure. The uncertainties in the THP influence the structure response. The stress field in the deformable tube is highly sensitive to the random characters of parameters $P$ and $k$. The finding failure probability relative to the necking is smaller the the failure probability relative to the wrinkling because the die let the tube to support the pression more than the imposed displacement. In the both cases (necking and wrinkling), the computational CPU time is very high because the limit state functions are implicit and the computation of the gradient must be done by the first order derivative approximation in each component of the random vector. This implies a repetitive call of the Abaqus program.

\section{CONCLUSION}

Structural reliability analysis is an approach that assists the design engineer to take into account all possible uncertainties during the design and construction phases and the lifetime of a structure in order to estimate the probabilities of failure.

Hydroforming process has a great industrial interest and for structural automotive components, it is now considered the only method in many cases. But the final manufacturing product can be unacceptable for a particular set of design parameters. This consideration of uncertainties on the mechanical properties, on the load ... increases the failure risk of the structures and the reliability approach is essential.

In this paper, we have proposed a numerical method to solve a reliability-hydroforming problem based on the finite elements approximation coupled with a response surface method. This numerical combination is efficient and gives accurate results in this nonlinear mechanical case but it have a great computational CPU cost. As future work, first, one must try to reduce them and secondly one can see other reliability approaches based on metamodels and numerical experience plans.

\section{REFERENCES}

[1] G. Cherouat A, Saanouni K, Hammi Y. Numerical improvement of thin tubes hydroforming with respect to ductile damage. I J of Mech Sc ;44:2427-2446, 2002

[2] Karthik V et al. Variability of sheet formability and formability testing. J of Mat Proc Technology; 121:350-362, 2002.

[3] Gantar G, Kuzman K. Optimization of stamping processes aiming at maximal process stability. $\mathrm{J}$ of Mat Proc Technology;167:237-243, 2005.

[4] Radi B, El Hami A. Reliability analysis of the metal forming process. Math and Comp Modelling ; 45:431-439, 2007.

[5] Nourelfath M, Nahas N. Quantized hopfield networks for reliability optimization. Reliab Eng Syst Safety 2003;81:191196.

[6] El Hami A, Radi B. Fiabilité et optimisation des systèmes. Paris : Ellipses; ISBN: 978-2-7298-6680-8, 2011. 